\title{
Hypertonic Saline Increases Vascular Permeability in the Rat Trachea by Producing Neurogenic Inflammation
}

\author{
Eisuke Umeno, ${ }^{\star \star 5}$ Donald M. McDonald, $* \| 1$ and Jay A. Nadel ${ }^{\star * \$}$ \\ ${ }^{*}$ Cardiovascular Research Institute and Departments of ${ }^{\prime \prime}$ Anatomy, ${ }^{\ddagger}$ Medicine, and ${ }^{\S}$ Physiology, \\ University of California, San Francisco, San Francisco, California 94143-0130
}

\begin{abstract}
In this study, we examined whether inhalation of hypertonic saline aerosols increases vascular permeability in the rat trachea, and we examined the role of neurogenic inflammation in this response. Stereological point counting was performed to measure the percent area occupied by Monastral blue-labeled blood vessels as a means of quantifying the increase in vascular permeability in tracheal whole mounts. Hypertonic saline aerosols (3.6-14.4\% $\mathrm{NaCl})$ increased vascular permeability in a dose-dependent fashion compared with $0.9 \% \mathrm{NaCl}$. Thus, the area density of Monastral blue-labeled vessels after inhalation of 3.6\% $\mathrm{NaCl}$ was greater (21.2 $\pm 3.5 \%$ mean $\pm \mathrm{SEM}, n=5)$ than after $0.9 \% \mathrm{NaCl}$ aerosol $(3.3 \pm 0.9 \%, n=5, P<0.5)$. The neutral endopeptidase inhibitor phosphoramidon $(2.5 \mathrm{mg} / \mathrm{kg}$, i.v.) significantly potentiated the increase of vascular permeability caused by $3.6 \% \mathrm{NaCl}$. Desensitization of sensory nerve endings by pretreatment with capsaicin markedly reduced the usual increase in vascular permeability caused by $3.6 \% \mathrm{NaCl}$, but the increase in vascular permeability induced by aerosolized substance $P\left(10^{-4} \mathrm{M}\right)$ was unchanged. These findings suggest that hypertonic saline increases vascular permeability in the rat trachea by stimulating the release of neuropeptides from sensory nerves. (J. Clin. Invest. 1990. 85:1905-1908.) postcapillary venule - neuropeptide - neutral endopeptidase • phosphoramidon • sensory nerve desensitization • capsaicin
\end{abstract}

\section{Introduction}

Mechanical and chemical irritation of the airways, and electrical stimulation of the vagus nerves cause the release of neuropeptides from sensory nerves in the airway mucosa. These neuropeptides cause neutrophil adhesion (1), increase vascular permeability (2), and cause smooth muscle contraction (3), gland secretion (4), and cough (5). This constellation of effects is termed "neurogenic inflammation."

Hypertonic saline causes neurogenic inflammation in the eye (6). Aerosols of hypertonic saline provoke cough (7), providing evidence that these aerosols stimulate sensory nerves. Therefore, we decided to examine whether inhaled hypertonic aerosols could increase vascular permeability in the rat tra-

Address reprint requests to Dr. Nadel, Cardiovascular Research Institute, Box 0130, University of California, San Francisco, CA 941430130.

Received for publication 29 November 1989 and in revised form 12 January 1990.

J. Clin. Invest.

(C) The American Society for Clinical Investigation, Inc. 0021-9738/90/06/1905/04 \$2.00

Volume 85, June 1990, 1905-1908 cheal mucosa and whether the release of sensory neuropeptides is involved in this response.

Neutral endopeptidase (NEP) ${ }^{1}$ is a membrane-bound enzyme which exists in airway cells that contain receptors for the neuropeptides released from the sensory nerves (8). NEP, by cleaving the neuropeptides, inactivates them and limits their actions (8). Furthermore, inhibitors of NEP (e.g., phosphoramidon), potentiate all of the airway effects of neurogenic inflammation (8). Therefore, we also examined whether the increased vascular permeability induced by inhalation of hypertonic saline aerosols is potentiated by the NEP inhibitor, phosphoramidon. We found that hypertonic saline aerosols $(3.6-14.4 \% \mathrm{NaCl})$ increased vascular permeability in a dosedependent fashion. This effect was prevented by desensitization of the sensory nerves by pretreatment with capsaicin and was potentiated by phosphoramidon.

\section{Methods}

We used 37 pathogen-free male rats of the F344 strain that weighed $240 \pm 2 \mathrm{~g}$ (mean $\pm \mathrm{SEM})$ and that were obtained from Charles River Breeding Laboratories, Wilmington, MA. The animals were anesthetized (sodium methohexital, $72 \mathrm{mg} / \mathrm{kg}$, i.p.). The larynx and upper trachea were exposed, the trachea just below the larynx was incised and an intubation tube was inserted $1 \mathrm{~mm}$ into the trachea. The animals were then ventilated artificially (frequency of 65 breaths $/ \mathrm{min}$, and tidal volume of $3 \mathrm{ml}$ ), using a constant-volume ventilator (model 680, Harvard Apparatus Co., Inc., Millis, MA). Aerosols were generated by an ultrasonic nebulizer (Pulmo-Sonic model 25, DeVibiss Co., Somerset, PA) at $0.2 \mathrm{ml} / \mathrm{min}$ and delivered via the tracheal tube for $2 \mathrm{~min}$ during ventilation with the respirator.

We used Monastral blue pigment to identify abnormally permeable venules. The particles of Monastral blue are too large to cross the endothelium of tracheal blood vessels with normal permeability. However, when the blood vessels become abnormally permeable, the pigment passes through gaps in the endothelium, and is trapped by the basal lamina, where it remains and thus labels the sites of extravasation $(1,9)$. A $3 \%$ suspension of Monastral blue (range of particle size, $50-300 \mathrm{~nm}$ ) (1) in $0.85 \% \mathrm{NaCl}$ (Sigma Chemical Co., St. Louis, MO) was sonicated in an ultrasonic cleaner for $5 \mathrm{~min}$, passed through a filter (pore size $5 \mu \mathrm{m}$, Millipore Corp., Bedford, MA), and injected into a femoral vein $(30 \mathrm{mg} / \mathrm{kg})$ at the beginning of the aerosol challenge. 5 min after the injection of Monastral blue, vascular perfusion with a fixative $(1 \%$ paraformaldehyde and $0.85 \% \mathrm{NaCl}$ in $50 \mathrm{mM}$ phosphate buffer, $\mathrm{pH}, 7.4$ ) was performed for $2 \mathrm{~min}$ with a vascular pressure of $120 \mathrm{~mm} \mathrm{Hg}$ via a cannula inserted through the left ventricle into the ascending aorta. Then the tracheas were removed, opened longitudinally along the ventral midline, and transferred to fresh fixative for $3 \mathrm{~h}$ at $4^{\circ} \mathrm{C}$. The tracheas were then flattened and prepared as whole mounts (1).

The number of abnormally permeable blood vessels in the tracheal whole mounts was estimated by using stereological point counting to determine the area density of the blood vessels labeled with Monastral

1. Abbreviations used in this paper: NEP, neutral endopeptidase. 
blue. Point counts were made of 20 regions located in the 6th through 25th intercartilaginous spaces on the right side of each whole mount. The counts were made by superimposing a computer-generated multipurpose test grid (line length $=25 \mathrm{~mm}$ [10]) on a televised image of the specimens magnified $\times 460$ with a stereomicroscope (Carl Zeiss, Inc., Wetzlar, Federal Republic of Germany). The area of each of the 20 regions measured was approximately $200,000 \mu \mathrm{m}^{2}$.

First, we studied the effect of increasing concentrations of inhaled $\mathrm{NaCl}$ aerosols $(0.9 \%, 3.6 \%, 7.2 \%$, and $14.4 \% ; n=5$ for each concentration) on vascular permeability.

We studied the effect of the selective NEP inhibitor, phosphoramidon, on the increase in vascular permeability caused by $3.6 \% \mathrm{NaCl}$ aerosol in five rats. Phosphoramidon $(2.5 \mathrm{mg} / \mathrm{kg}$, i.v.; Peninsula Laboratories, Inc., Belmont, $\mathrm{CA}$ ) dissolved in $0.9 \% \mathrm{NaCl}$ was injected over a 10 -s period $5 \mathrm{~min}$ before the inhalation of $3.6 \% \mathrm{NaCl}$ aerosols.

Next, we studied the effect of desensitization of the sensory nerves by a high dose of capsaicin. These rats received subcutaneous injections of gradually increasing doses of capsaicin $(4,8$, and $15 \mathrm{mg})$ over a period of $24 \mathrm{~h}$, according to a method described previously (6). The injections of capsaicin were given, using a $1 \%$ solution of capsaicin dissolved in $10 \%$ ethanol and $10 \%$ Tween 80 in $0.9 \% \mathrm{NaCl}$, while the animals were anesthetized. $5 \mathrm{~d}$ after the last dose of capsaicin, airway challenge with $3.6 \% \mathrm{NaCl}$ aerosol was performed in four rats.

Because capsaicin pretreatment could also have effects on the venules themselves, we also examined the effect of capsaicin pretreatment on the increase in vascular permeability produced by substance $P$ aerosols. Specifically, we determined the effect of substance $P\left(10^{-4} \mathrm{M}\right.$; Peninsula Laboratories, Inc.), dissolved in $0.01 \mathrm{~N}$ acetic acid in $0.9 \%$ $\mathrm{NaCl}$, and aerosolized for $2 \mathrm{~min}$, on vascular permeability using Monastral blue. We chose this concentration of substance $P$ aerosol because it caused large enough increases in vascular permeability to examine the possibility that capsaicin might cause tachyphylaxis of the responses of the blood vessels themselves. Before inhalation of substance $\mathbf{P}$, four rats received increasing doses of capsaicin. Four additional control rats received only the vehicle of capsaicin subcutaneously during the same schedule of injections.

The area occupied by Monastral blue-labeled venules was expressed as the percentage of the total area of tracheal mucosa measured. Average values are expressed as the mean \pm SEM (standard error of the mean). The significance of differences was assessed by one-way analysis of variance or Student's $t$ test. The difference between groups was considered significant when $P<0.05$.

\section{Results}

Inhalation of aerosolized hypertonic saline for $2 \mathrm{~min}$ increased the area occupied by Monastral blue-labeled postcapillary venules in the tracheas of pathogen-free rats. The increase in vascular permeability occurred in a concentration-dependent fashion (Fig. 1). Because $3.6 \% \mathrm{NaCl}$ aerosols caused significantly greater Monastral blue labeling of the venules than did $0.9 \% \mathrm{NaCl}$ aerosols, we used $3.6 \% \mathrm{NaCl}$ in all subsequent studies.

Pretreatment with the NEP inhibitor phosphoramidon (2.5 $\mathrm{mg} / \mathrm{kg}$, i.v.) potentiated significantly the increase in vascular permeability caused by $3.6 \% \mathrm{NaCl}$ aerosols $(P<0.001 ; n=5$; Fig. 2, left vs. middle column). When rats were pretreated subcutaneously with increasing concentrations of capsaicin, the effect of inhaled aerosols of $3.6 \% \mathrm{NaCl}$ was inhibited $(P$ $<0.001$ compared to the effect of $3.6 \% \mathrm{NaCl}$ alone; $n=5$; Fig. 2 , right vs. middle column).

Inhalation of substance $P$ aerosols $\left(10^{-4} \mathrm{M}\right.$ for $\left.2 \mathrm{~min}\right)$ increased vascular permeability ( $n=4$; Fig. 3 , left column). However, in contrast to that produced by hypertonic saline, the increase in vascular permeability caused by substance $P$

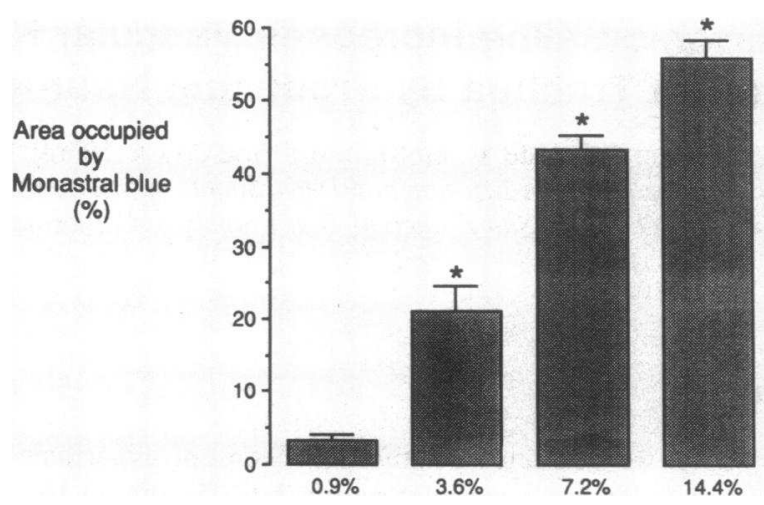

Figure 1. Histogram comparing the effects of inhalation of various concentrations of aerosolized $\mathrm{NaCl}$ on vascular permeability in tracheal whole mounts in pathogen-free rats (mean $\pm \mathrm{SEM} ; n=5$ per group). Vascular permeability was evaluated by measuring the area density of Monastral blue-labeled blood vessels by stereological point counting. Hypertonic $\mathrm{NaCl}$ increased vascular permeability in a concentration-dependent fashion. All concentrations of hypertonic saline produced significantly more extravasation than did $0.9 \% \mathrm{NaCl}$ $\left({ }^{*} P<0.05\right)$

was unaffected by capsaicin pretreatment $(P>0.05 ; n=4$ for each group; Fig. 3, right column).

\section{Discussion}

These studies show that inhalation of hypertonic saline aerosols causes increases in vascular permeability in the rat trachea. Compared with neurogenic inflammatory increases in vascular permeability induced by intravenous capsaicin (11),

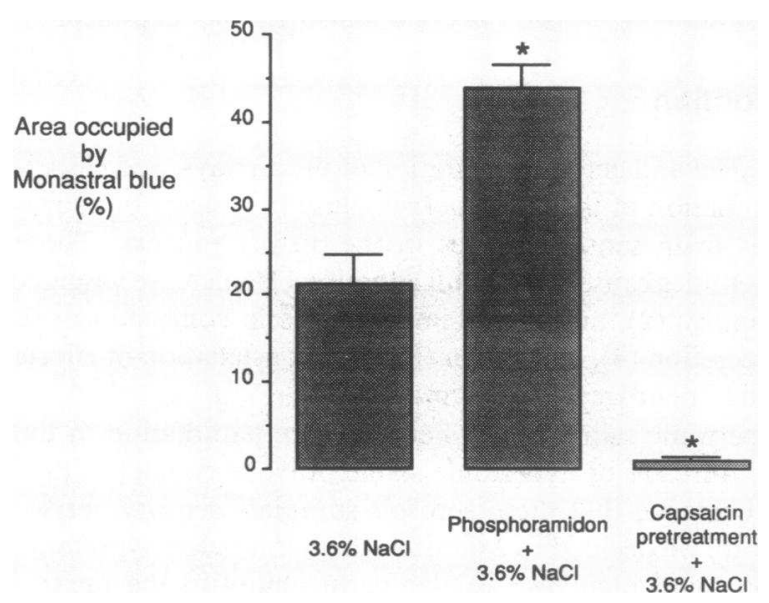

Figure 2. Histogram comparing the effects of inhalation of $3.6 \%$ $\mathrm{NaCl}$ aerosols on vascular permeability in the tracheas of pathogenfree rats (mean \pm SEM). Vascular permeability was evaluated by measuring the area density of Monastral blue-labeled blood vessels by stereological point counting. Compared to the effect of inhalation of $3.6 \% \mathrm{NaCl}$ aerosols alone $(n=5$; left column), pretreatment with the NEP inhibitor phosphoramidon $(2.5 \mathrm{mg} / \mathrm{kg}$, i.v.) exaggerated the hypertonic saline-induced response $\left({ }^{*} P<0.001, n=5\right.$; middle column). Pretreatment with increasing concentrations of capsaicin to desensitize the sensory nerves inhibited the response to hypertonic saline $\left({ }^{*} P<0.001, n=4\right.$; right column $)$. 


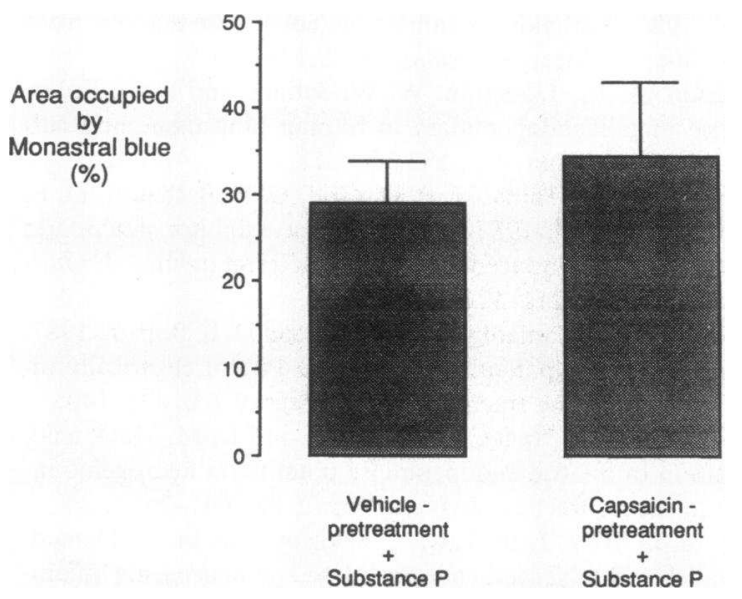

Figure 3. Histogram comparing the effects of inhalation of aerosols of substance $P\left(10^{-4} \mathrm{M}\right)$ for 2 min on vascular permeability in the tracheas of pathogen-free rats (mean $\pm \mathrm{SEM} ; n=4$ in each group). Vascular permeability was evaluated by measuring the area density of Monastral blue-labeled vessels by stereologic point counting. In animals pretreated with only the vehicle for capsaicin, inhalation of aerosols of substance $P$ increased vascular permeability (left column). Pretreatment with increasing concentrations of capsaicin to desensitize the sensory nerves had no significant effect on substance P-induced increases in vascular permeability $(P>0.05$; right column).

hypertonic saline aerosols cause very potent responses. These responses were dose dependent and showed no maximum at the doses studied. Significant effects occurred in concentrations at or below those used to trigger bronchospasm (12) or cough (7) in humans.

To investigate the possible role of neuropeptides released from sensory nerves (so-called "neurogenic inflammation") in hypertonic saline-induced increases in vascular permeability, we took two approaches. The first approach involved the fact that the effects of released neuropeptides are modulated by the enzyme NEP (8). This membrane-bound enzyme is located in airway cells (13-16). By cleaving and thus inactivating neuropeptides (e.g., substance $P$ ) released from sensory nerves, NEP limits the effects of neurogenic inflammation. Thus, the increased vascular permeability in the trachea produced by exogenously delivered substance $P$ and by neuropeptides released endogenously from the sensory nerves is potentiated by the NEP inhibitor phosphoramidon (17). Similarly, we reasoned that if hypertonic saline increased vascular permeability by neural release of peptides, then the effect should be potentiated by inhibiting the normal activity of NEP. In our present studies, the fact that pretreatment with the selective NEP inhibitor phosphoramidon potentiated the increase in vascular permeability induced by hypertonic saline suggests that small peptides are involved in the response, rather than mediators such as histamine, serotonin, prostaglandins, or leukotrienes, which are not cleaved by NEP. Our second approach involved the chemical desensitization of the sensory nerves. Jancso (6) have shown that capsaicin pretreatment causes desensitization of the sensory nerves to subsequent mechanical and chemical stimulation (6). In our present studies, pretreatment with capsaicin completely inhibited the usual increase in vascular permeability induced by hypertonic saline. The fact that responses to substance $P$ were unaffected by capsaicin pretreat- ment indicates that the ability of the vessels to respond to neuropeptides remained intact.

Together, our results implicate strongly neurogenic inflammation in the response to hypertonic saline. When the sensory nerves to the airways are stimulated to release neuropeptides, increased vascular permeability ensues (2). Although the present studies indicate that hypertonic saline increases vascular permeability in the airways, it is not known whether the effect is due to the increased osmolarity or due to an alteration in the concentration of a specific ion. Furthermore, the exact series of events between the time of deposition of the aerosol particles on the airway surface and the neurogenic responses remains unknown.

Previous studies have shown that pharmacologic inhibition of NEP activity with phosphoramidon potentiates the increase in vascular permeability that occurs with chemical (and electrical) stimulation of vagal sensory axons (17). Similarly, our present results show that phosphoramidon exaggerates the increased vascular permeability induced by hypertonic saline aerosols. Furthermore, it has been shown in rats that, by decreasing NEP activity, Sendai virus (11) and other respiratory tract infections (18) potentiate the increase in vascular permeability associated with delivery of exogenous tachykinins and with the release of endogenous neuropeptides. Inhalation of air pollutants (19) and cigarette smoke (20) also decreases NEP activity and causes exaggerated airway responses to neuropeptides (e.g., substance P). In the context of the present results, these previous findings suggest that when NEP activity is decreased by exogenous stimuli (e.g., pollutants, viral infections, cigarette smoke) or by a disease process, exaggerated airway responses to hyperpnea and to hypertonic saline aerosols may occur.

We speculate that many stimuli (e.g., chemicals, dusts, hyperpnea) may stimulate neurogenic inflammatory responses. In the presence of normal NEP activity, the neuropeptides that are released are cleaved and inactivated, so the concentration of the peptides that reach the receptors on target cells is low, and the responses are mild and clinically nondetectable. However, when NEP activity is decreased, these responses become exaggerated and may contribute to the pathogenesis of diseases such as asthma.

\section{Acknowledgments}

The authors thank Amy Haskell and Lynne Calonico for technical help.

This study was supported in part by program project grant HL-24136 from the National Institutes of Health.

\section{References}

1. McDonald, D. M. 1988. Neurogenic inflammation in the rat trachea. I. Changes in venules, leucocytes, and epithelial cells. J. Neurocytol. 17:583-603.

2. Lundberg, J. M., and A. Saria. 1983. Capsaicin-induced desensitization of airway mucosa to cigarette smoke, mechanical and chemical irritants. Nature (Lond.). 302:251-253.

3. Lundberg, J. M., A. Saria, E. Brodin, S. Rosell, and K. Folkers. 1983. A substance $P$ antagonist inhibits vagally induced increase in vascular permeability and bronchial smooth muscle contraction in the guinea pig. Proc. Natl. Acad. Sci. USA. 80:1120-1124.

4. Borson, D. B., R. Corrales, S. Varsano, M. Gold, N. Viro, G. 
Caughey, J. Ramachandran, and J. A. Nadel. 1987. Enkephalinase inhibitors potentiate substance P-induced secretion of ${ }^{35} \mathrm{SO}_{4}$-macromolecules from ferret trachea. Exp. Lung Res. 12:21-36.

5. Kohrogi, H., P. D. Graf, K. Sekizawa, D. B. Borson, and J. A Nadel. 1988. Neutral endopeptidase inhibitors potentiate substance $P$ and capsaicin-induced cough in awake guinea pigs. J. Clin. Invest. 82:2063-2068.

6. Jancso, N. 1960. Role of the nerve terminals in the mechanism of inflammatory reactions. Bull. Millard Fillmore Hosp. 7:53-77.

7. Eschenbacher, W. L., H. A. Boushey, and D. Sheppard. 1984. Alteration in osmolarity of inhaled aerosols cause bronchoconstriction and cough, but absence of a permeant anion causes cough alone. Am. Rev. Respir. Dis. 129:211-215.

8. Nadel, J. A. Neutral endopeptidase modulation of neurogenic inflammation in airways. Eur. Respir. $J$. In press.

9. Joris, I., U. DeGirolami, K. Worthman, and G. Majno. 1982. Vascular labelling with Monastral blue B. Stain Technol. 57:177-183.

10. Weibel, E. R. 1979. Stereological Methods. Practical Methods for Biological Morphometry. Academic Press, Ltd., London.

11. Piedimonte, G., J. A. Nadel, E. Umeno, D. M. McDonald. 1990. Sendai virus infection potentiates neurogenic inflammation in the rat trachea. J. Appl. Physiol. 68:754-760.

12. Schoeffel, R. E., S. D. Anderson, and R. E. C. Altounyan. 1981. Bronchial hyperreactivity in response to inhalation of ultrasonically nebulized solutions of distilled water and saline. Br. Med. J. 283:1285-1287.

13. Borson, D. B., B. Malfroy, M. Gold, J. Ramachandran, and
J. A. Nadel. 1986. Tachykinins inhibit enkephalinase activity from tracheas and lungs of ferrets. Physiologist. 29:174.

14. Johnson, A. R., J. Ashton, W. W. Schulz, and E. G. Erdos. 1985. Neutral metalloendopeptidase in human lung tissue and cultured cells. Am. Rev. Respir. Dis. 132:564-568.

15. Sekizawa, K., J. Tamaoki, P. D. Graf, C. B. Basbaum, D. B. Borson, and J. A. Nadel. 1987. Enkephalinase inhibitor potentiates mammalian tachykinin-induced contraction in ferret trachea. J. Pharmacol. Exp. Ther. 243:1211-1217.

16. Sekizawa, K., J. Tamaoki, J. A. Nadel, and D. B. Borson. 1987. Enkephalinase inhibitor potentiates substance P- and electrically induced contraction in ferret trachea. J. Appl. Physiol. 63:1401-1405.

17. Umeno, E., J. A. Nadel, H.-T. Huang, and D. M. McDonald. 1989. Inhibition of neutral endopeptidase potentiates neurogenic inflammation in the rat trachea. J. Appl. Physiol. 66:2647-2652.

18. Borson, D. B., J. J. Brokaw, K. Sekizawa, D. M. McDonald, and J. A. Nadel. 1989. Neutral endopeptidase and neurogenic inflammation in rats with respiratory infections. J. Appl. Physiol. 66:26532658.

19. Sheppard, D., J. E. Thompson, L. Scypinski, D. Dusser, J. A. Nadel, and D. B. Borson. 1988. Toluene diisocyanate increases airway responsiveness to substance $P$ and decreases airway enkephalinase. $J$. Clin. Invest. 81:1111-1115.

20. Dusser, D. J., T. D. Djokic, D. B. Borson, and J. A. Nadel. 1989. Cigarette smoke induces bronchoconstrictor hyperresponsiveness to substance $P$ and inactivates airway neutral endopeptidase in the guinea pig: possible role of free radicals. J. Clin. Invest. 84:900-906. 